\title{
Cervical cancer: applications of genotyping for the screening in human papilomavirus (HPV)
}

\author{
Silva, V.M1; Santos, G.S2; Silva J.F.S3; Nascimento, E.R.S4; Wanderley, M.C.A5; Godone, \\ R.L.N6
}

1,2,3,4Estudante do Curso de Biomedicina- UNINASSAU- Caruaru; 5,6Docente do curso de Biomedicina- UNINASSAU- Caruaru

\section{ABSTRACT}

Introduction: Cervical cancer is considered a serious public health problem, especially in underdeveloped countries. The causal factor of the disease is infection of the vaginal mucosa by human papillomavirus (HPV). HPV consists of more than 130 genotypes, the genotypes of higher prevalence in histopathological diagnoses are subtypes 16 and 18. Currently diagnostic techniques such as pap smears and HPV test do not cover viral subtypes, important for identifying the presence of the high-risk genotypes in the sample, stopping the progression to cervical cancer. Genotyping consists of the secondary screening method for identification of viral subtypes, bringing promising prospects for the early diagnosis of the disease. Objective: To evaluate genotyping as an alternative for the early identification of the high risk HPV genotype as a possibility for the prevention of cervical cancer. Methodology: Electronic data platforms (MEDLINE, PubMed and Scopus) were consulted from 2012 to 2016, using the descriptors: "cervical cancer", "HPV" and "genotyping". Results and Discussion: With the applications of genotyping, it is possible to detect elements that indicate the presence of highrisk HPV subtypes in the positive samples in the initial screening techniques. Through the detection of the p16 and ki-67 proteins, which are expressed in the stages of the cell cycle, the decrease of these biomarkers indicates a deregulation in the cellular proliferation, indicating the oncogenic manifestation. The advancement of technologies has contributed to add improvements to screening programs and thus make them more effective in detecting women who have a greater potential for progression to cervical cancer. Conclusion: Although several techniques for identifying cancer caused by HPV have already been applied, they do not yet have coverage for a quick and accurate diagnosis of the viral genotype.

Keywords: Cervical cancer; Genotyping; Screening
*Correspondence to Author:

Silva, V.M

Estudante do Curso de Biomedicina- UNINASSAU- Caruaru

How to cite this article:

Silva, V.M; Santos, G.S; Silva J.F.S; Nascimento, E.R.S; Wanderley, M.C.A; Godone, R.L.N. Cervical cancer: applications of genotyping for the screening in human papilomavirus (HPV).International Journal of Biomedical Engineering Research, 2018, 1:2

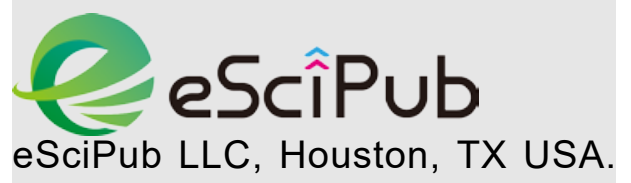

Website: http://escipub.com/ 